\title{
Revealing anti-viral potential of Bio-active therapeutics targeting SARS-CoV2- polymerase (RdRp) in combating COVID-19: Molecular Investigation on Indian traditional medicines \\ D.Sivaraman ${ }^{1,2,3}$, P.S.Pradeep ${ }^{1}$
}

\begin{abstract}
Affiliations
${ }^{1}$ Department of Pharmacology and Toxicology, Centre for Laboratory Animal Technology and Research, Sathyabama Institute of Science and Technology, Jeppiaar Nagar, Chennai - 600 119, Tamil Nadu, India.

${ }^{2}$ School of Pharmacy, Sathyabama Institute of Science and Technology, Jeppiaar Nagar, Chennai - 600 119, Tamil Nadu, India.

${ }^{3}$ Chinese Association for Laboratory Animal Sciences, Chaoyang District, Beijing, 100021, P.R.China
\end{abstract}

Corresponding Author $\quad$ : D.Sivaraman

E-mail $\quad$ : sivaramand83@gmail.com

Telephone $\quad$ : 91-9841575334/91-044-25522874.

Corresponding Address $\quad$ : Sathyabama Institute of Science and Technology, Jeppiaar Nagar, Rajiv Gandhi road, Chennai - 600 119, Tamil Nadu, India.

\begin{abstract}
Spread of severe acute respiratory syndrome coronavirus (SARS-CoV-2) made a historic transition between December 2019 to March 2020. In the present scenario SARS-CoV-2 as becomes a major burden on public health and economic stability of societies around the globe. From the substantial evidences gained from the pandemic of SARS-CoV-2 and MERS-CoV (Middle East respiratory syndrome coronavirus), scientists and clinicians strongly believes that these pathogenic viruses share common homology of some biologically active enzymes which includes RNA-dependent RNA polymerase (RdRP), 3-chymotrypsin-like protease (3CL ${ }^{\mathrm{pro}}$ ), papain-like protease $\left(\mathrm{PL}^{\mathrm{pro}}\right)$ etc. RdRP relatively grabs higher level of clinical importance in comparison with other enzyme target. Indian system of traditional medicine pioneering the therapy towards infectious disease since several centuries. In view of this potential therapeutic leads from
\end{abstract}


some of the Indian medicines along with standard drug favipiravir subjected to docking investigation targeting SARS-CoV-2- RNA dependent RNA polymerase (RdRp). Residual proximity analysis reveals 18 out of 28 compounds reveals potential binding affinity of about $100 \%$ with the target amino acid residue (618 ASP, 760 ASP,761 ASP), 7 out of 28 reveals $75 \%$ binding efficacy and 3 out of 28 reveals $25 \%$ binding efficacy with that of the target residue. Hence further clinical validation may be warranted with proper in-vitro and in-vivo studies prior to the clinical recommendation in treating COVID-19 patient's.

Key words: SARS-CoV-2, COVID-19, Indian medicines, Phytotherapeutics, Favipiravir

\section{Introduction}

Pandemic spread of COVID-19 caused by severe acute respiratory syndrome coronavirus (SARS-CoV-2) has now shifted across the boundaries, authoritative data issued by WHO on 29 March 2020 intensifies the severity of viral invasion that prevails in more than 190 countries. Fatality index attaining greater hikes on hourly basis, according to recent demography global mortality due to COVID-19 was found to be 29,957 deaths ${ }^{1}$. Countries like Italy (92,472 cases), Spain (72,248 cases), Germany $(52,547)$ and Iran $(35,408$ cases) seems severely affected with striking invasion of disease.

As per the epidemiological investigations is concern the spectrum of COVID-19 in India majorly due to imported infection rather than the acquired local transmission. India reported with 3 positive cases on 1 March 2020, whereas it has reached 979 on 29 March 2020 these data's alarms the need of preventive measure that has to be focused with higher priority.

China become a global role model in advocating the traditional chinese medicine (TCM) along with conventional therapy for managing COVID-19 which was evidenced by initiation of several multi centric randomized trials for validating the safety and efficacy of TCM in patients reported with COVID-19 ${ }^{2-5}$. National health commission of china framed a policy guideline for ensures the efficacy of TCM in treated patients ${ }^{6,7}$.

Recently on 28 March 2020, prime minister of India made a productive discussion with professional in the field of Indian medicine regarding opportunities of availing efficacious Indian medicines with evidence based interventional claim for controlling COVID-19 as prophylactic and therapeutic as well. Indian system of traditional medicine pioneering the therapy towards infectious disease since several centuries, formulations like Nilavembu Kudineer (NVK) comprises of 9 individual herbs has proven clinical track record in management of dengue viral 
infection during outbreak in southern zone of India ${ }^{8}$. This formulation is officially recommended by the department of health and family welfare, Government of Tamil Nadu for managing dengue crisis. Research outcome strongly evident the anti-viral potential of the formulation NVK against dengue and chikungunya viral cultures ${ }^{9}$. NVK also claiming the antipyretic and anti-inflammatory property as per the published records ${ }^{10}$. Other indigenous medicine called Kaba sura kudineer (KSK) comprises of 15 herbs is a recommend for managing swine flu by national health portal (NHP), Government of India ${ }^{11-13}$.

There are several enzymes involved in the pathogenesis of SARS-CoV-2 of which the enzyme RNA dependent RNA polymerase (RdRP) that exist only on the viral genome relatively grabs higher level of therapeutic importance due to its versatile action in mediating nonstructural protein (nsp 12) essential for viral replication ${ }^{14,15}$. Drugs that inhibits this RdRP activity may have expected to halt the replication of viral genome and thereby control disease progression ${ }^{16,17}$. Recent clinical outcomes reveals improved efficacy of favipiravir (RdRP) inhibitor with estimated recovery rate of $71.43 \%$ in treated cases ${ }^{18}$.

Still now there is no proper documented evidence supporting the efficacy of prescribed indian medicines on targeting SARS-CoV-2- RNA dependent RNA polymerase (RdRp). Hence present study aimed at exploring RdRp enzyme inhibition potential of both the formulations (Nilavembu Kudineer and Kaba sura kudineer) using predictive molecular docking assay.

\section{Materials and Methods}

\subsection{Protein-ligand docking}

Molecular docking investigation was performed using Auto Dock version 4 which predicts interaction binding affinity between selected therapeutic lead with that of the protein target (SARSCoV-2 virus spike RNA dependent RNA polymerase- RdRp).

\subsection{Protein preparation}

Three dimensional (3D) structure of SARS-CoV-2 virus spike RNA dependent RNA polymerase with protein data bank (PDB)-6NUR (Figure 1) retrieved from Research Collaboratory for Structural Bioinformatics (RCSB). Protein structure were cleaned by removing the existing lead components, water molecules cleaved, Gasteiger charges computed with inclusion of polar hydrogens, merging of non-polar and rotatable bonds were defined using Auto Dock $4{ }^{19}$.

\subsection{Active site prediciton on the target protein}


Active amino acids involved in mediating the enzyme activity was predicted using ramachandran plot indicating localization of the residues on the A chain of the target enzyme. Prediction by MolProbity server and also through literature survey. As shown in Figure 2.

\subsection{Ligand model preparation}

Structures of the bioactive lead compounds such as 6-Shogaol, 6-Gingerol, Beta Sitosterol, Piperidine, Apigenin, Piperine, Quercetin, Chlorogenic Acid, Beta-Pinene, Alpha-Bisabolol ,Andrographolide, Bharangin, Carvacrol, Cissamine ,Costunolide, Cucurbitacin B, Gallic acid, Linoleic acid, Pellitorine, Rutin, Santalic acid, Spathulenol, Vasicine, Vetiverol , Cynaropicrin, Eugenol, Thymol, Vitexin along with standard drug Favipiravir subjected to docking investigation were outlined using ChemDraw sketch software and converted from two dimension (2D) to3D structures. Table 2: Summarizing 2D and 3D structure of Bio-active therapeutic ligand subjected to molecular docking Investigation against SARS-CoV-2 virus spike RNA dependent RNA polymerase (PDB)-6NUR

\subsection{Docking simulations}

3D componential structure of lead molecules and protein were docked using AutoDock analytical tool version 4. Affinity (grid) maps of $\times \times \AA$ grid points and $0.375 \AA$ spacing were generated using the Autogrid program. AutoDock parameter set- and distance-dependent dielectric functions were used in the calculation of the van der Waals and the electrostatic terms, respectively. Docking simulations were performed using the programmed algorithm inbuilt with pre automation in the software 20. Initial position, orientation, and torsions of the ligand molecules were set randomly. All rotatable torsions were released during docking. Each docking experiment was derived from 2 different runs that were set to terminate after a maximum of 250000 energy evaluations. The population size was set to 150 . During the search, a translational step of $0.2 \AA$, and quaternion and torsion steps of 5 were applied.

\section{Results and Discussion}

\subsection{Molecular docking analysis}

Docking becomes a reliable drug discovery tools for optimizing the potential lead molecules against selective target. Docking score implicates the binding affinity between the lead and target higher the negativity in the value that showcase the level of potency of the drug ${ }^{21}$. Total of 28 bioactive lead compounds from reported data's of the herbs belongs to both the formulations (9 herbs from NVK and 15 from KSK) which includes 6-Shogaol, 6-Gingerol, Beta Sitosterol, 
Piperidine, Apigenin, Piperine, Quercetin, Chlorogenic Acid, Beta-Pinene, Alpha-Bisabolol ,Andrographolide, Bharangin, Carvacrol, Cissamine ,Costunolide, Cucurbitacin B, Gallic acid, Linoleic acid, Pellitorine, Rutin, Santalic acid, Spathulenol, Vasicine, Vetiverol, Cynaropicrin, Eugenol, Thymol, Vitexin along with standard drug Favipiravir subjected to docking investigation. Interaction sequential analysis proves that the amino acid residue (618 ASP, 760 ASP,761 ASP) present on the active site potentially determines the enzymatic action of RdRp in deriving the nonstructural protein non-structural protein $12^{22}$, there by binding on these potential amino acids have higher chances of enzyme inhibition.

From the library of the screened compounds 18 leads such including 6-Shogaol, 6Gingerol, Beta Sitosterol, Piperidine, Apigenin, Piperine, Quercetin, Alpha-Bisabolol, Andrographolide, Carvacrol, Cissamine, Costunolide, Cucurbitacin B ,Linoleic acid , Pellitorine, Rutin, Vetiverol and Cynaropicrin reveals potential binding affinity of about 100\% with the target amino acid residue. 7 leads (Chlorogenic Acid, Bharangin, Gallic acid, Spathulenol,V asicine ,pThymol and Vitexin) out of 28 reveals $75 \%$ binding efficacy and 3 out of 28 reveals $25 \%$ binding efficacy with that of the target residue. 3 leads (Beta-Pinene, Santalic acid and Eugenol) out of 28 reveals $25 \%$ binding efficacy with that of the target residue. Table 1: Summarizing the docking score and representing the interaction analysis plot with best binding docking pose of phytochemicals from the herbs of Kapa Sura Kudineer and Nilavembu Kudineer with that of the selected target.

\section{Conclusion}

Emerging SARS-CoV-2 infection rates urge the need of immunonutrient that has a tendency to strengthen the immune system by adequately enhancing humoral backup. In conclusion lead molecules from alternate and complementary therapeutic source provokes promising potential which grabs the attention of the researcher in the field of new drug discovery. Hence further clinical validation may be warranted with proper in-vitro and in-vivo studies prior to the clinical recommendation in treating COVID-19 patient's.

Acknowledgements: The Ministry of AYUSH (Ayurveda, Yoga \& Naturopathy, Unani, Siddha and Homoeopathy), Government of India. Indian Council of Medical Research (ICMR), Government of India, Central Council for Research in Siddha (CCRS), Tamil Nadu, India, National Institute of Siddha (NIS), Chennai, Tamil Nadu, India. State Licensing Authority for Indian Medicine (IM), Chennai, Tamil Nadu, India. The Tamil Nadu Dr. M.G.R. Medical 
University, Chennai, Tamil Nadu, India. Govt. Siddha Medical College, Chennai, Tamil Nadu, India. Chinese Association for Laboratory Animal Sciences (CALA),P.R.China.

Author contributions: D.Sivaraman and P.S.Pradeep equally involved in study design, Simulation, data collection and compilation involved in the study .

Competing interests: The authors declare no competing interests.

\section{References}

1. WHO Coronavirus disease (COVID-2019) situation report - 69, 2020 (accessed March 30,2020).https://www.who.int/docs/default-source/coronaviruse/situation-reports/ 20200329-sitrep-69-covid-19.pdf?sfvrsn=8d6620fa_2

2. Yang Yang et al. Traditional Chinese Medicine in the Treatment of Patients Infected with 2019-New Coronavirus (SARS-CoV-2): A Review and Perspective. Int. J. Biol. Sci. 2020;16:1706-1717.

3. Luo H, Tang QL, Shang YX, Liang SB, Yang M, Robinson N, et al. Can Chinese Medicine Be Used for Prevention of Corona Virus Disease 2019 (COVID-19)? A Review of Historical Classics, Research Evidence and Current Prevention Programs. Chin J Integr Med. 2020.

4. Tong X, Li A, Zhang Z, Duan J, Chen X, Hua C, et al. TCM treatment of infectious atypical pneumonia--a report of 16 cases. J Tradit Chin Med. 2004; 24: 266-9.

5. Liu X, Zhang M, He L, Li Y. Chinese herbs combined with Western medicine for severe acute respiratory syndrome (SARS). Cochrane Database Syst Rev. 2012; 10: Cd004882.

6. National Health Commission of the People's Republic of China. Transcript of press conference in 17, February, 2020. http://www.nhc.gov.cn/xcs/s3574/ 202002/f12a62d10c2a48c6895cedf2faea6e1f. shtml. 2020.

7. National Health Commission of the People's Republic of China. Notice on the issunance of guidelines of diagnosis and treatment for 2019-nCoV infected pneumonia (version 6). 6 ed;http://www.nhc.gov.cn/yzygj/s7653p/202002/8334a8326dd94d329df351d7da8aefc2.s html?from=timeline. 2020.

8. Parasuraman $\mathrm{G}$ et al. Dengue infection in India: A systematic review and meta-analysis. PLOS Neglected tropical disease.2018;1-29. 
9. Jain $\mathbf{J}$ et al. Antiviral activity of ethanolic extract of Nilavembu Kudineer against dengue and chikungunya virus through in vitro evaluation. J Ayurveda Integr Med. 2019. DOI: 10.1016/j.jaim.2018.05.006.

10. Anbarasu K et al. Antipyretic, anti-inflammatory and analgesic properties of nilavembu kudineer choornam: a classical preparation used in the treatment of chikungunya fever. Asian Pac J Trop Med. 2011;4:819-823.

11. Siddha perspective of managing swine flu with Kaba sura kudineer. https://www.nhp.gov.in/swine-flu_mtl (accessed on 30 March 2020)

12. Uthamarayan KS, Siddha Maruthuvanga churukkam, Directorate of Indian Medicine \& Homeopathy, Chennai- 106, 2006.

13. Murugesa Mudaliar KS. Siddha Materia Medica, Directorate of Indian Medicine \& Homeopathy, Chennai-106, 2013.

14. Anthony R. Coronaviruses: An Overview of Their Replication and Pathogenesis. Methods Mol Biol. 2015; 1282: 1-23.

15. Zumla A et al. Coronaviruses — drug discovery and therapeutic options. Nat. Rev. Drug Discov.2016; 15: 327-347.

16. Liying Dong, Shasha Hu, Jianjun Gao. Discovering drugs to treat coronavirus disease 2019 (COVID-19). Drug Discoveries \& Therapeutics. 2020; 14:58-60.

17. Chang C, Jianying H, Zhenshun $C$ et al. Favipiravir versus Arbidol for COVID-19: A Randomized Clinical Trial. MedRxiv.2020. (accessed March 24,2020). https://doi.org/10.1101/2020.03.17.20037432.

18. Huang A et al. Virtual Screening and Molecular Dynamics on Blockage of Key Drug Targets as Treatment for COVID-19 Caused by SARS-CoV-2. Preprints 2020, 2020030239. https://www.preprints.org/manuscript/202003.0239/v1. (accessed March 29,2020).

19. Stefano F, Ruth H, Michael EP, Michel S, David SG, Arthur J. Olson. Computational protein-ligand docking and virtual drug screening with the AutoDock suite. Nat Protoc. 2016; 11: 905-919.

20. Osterberg F, Morris GM, Sanner MF, Olson AJ, Goodsell DS. Automated docking to multiple target structures: incorporation of protein mobility and structural water heterogeneity in AutoDock. Proteins. 2002; 46:34-40. 
21. Evanthia L, George S, Demetrios KV, Zoe C. Structure-Based Virtual Screening for Drug Discovery: Principles, Applications and Recent Advances. Curr Top Med Chem. 2014 ; 14: 1923-1938.

22. Aartjan JW. The RNA polymerase activity of SARS-coronavirus nsp12 is primer dependent. Nucleic Acids Research, 2010, Vol. 38, No. 1 203-214

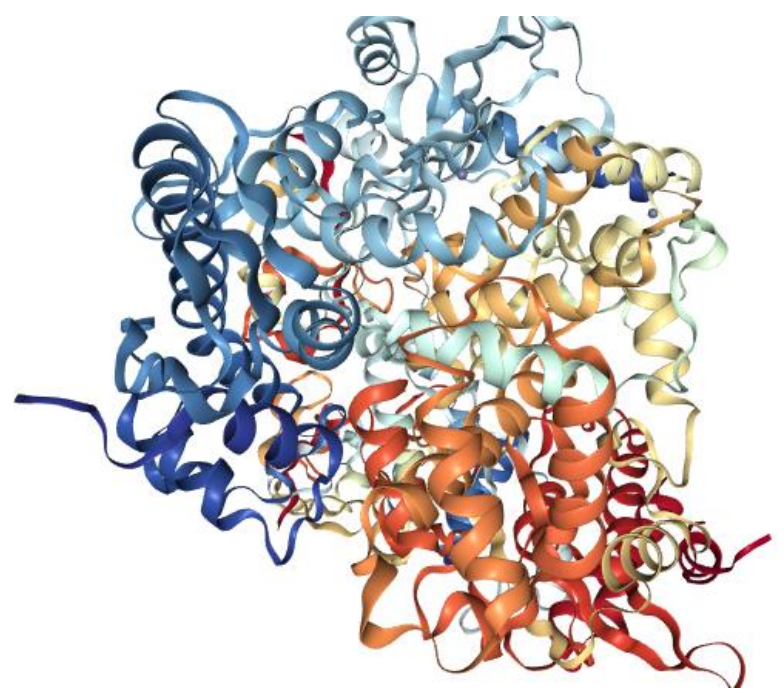

Figure 1. 3D structure of SARS-CoV-2 virus spike RNA dependent RNA polymerase (PDB)-6NUR

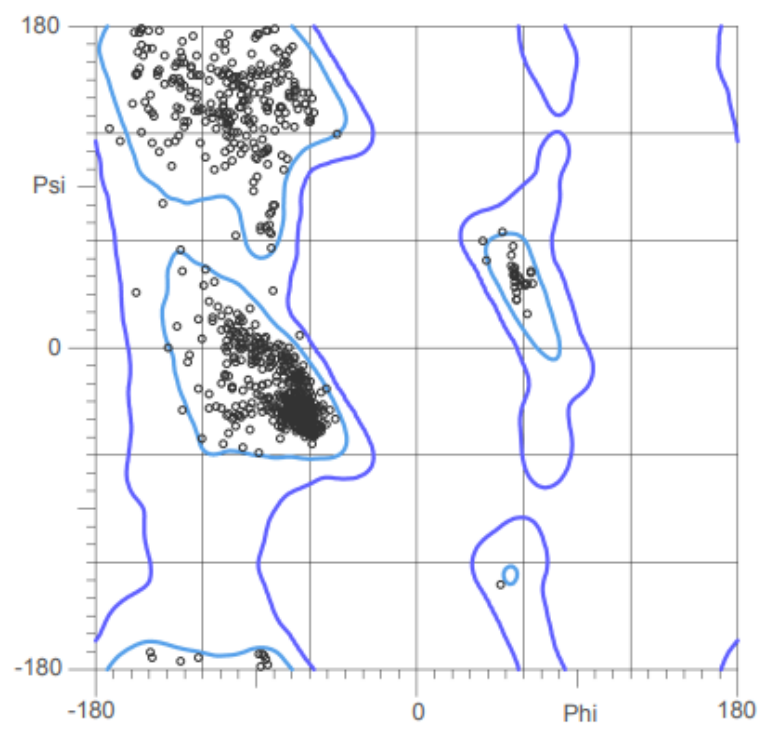

Figure 2. Ramachandran plot indicating amino acid resides in cluster of A- Chain 
Table 1: Summarizing the docking score and representing the interaction analysis plot with best binding docking pose of phytochemicals from the herbs of Kapa Sura Kudineer and Nilavembu Kudineer

\begin{tabular}{|c|c|c|c|c|c|}
\hline $\begin{array}{l}\text { S.N } \\
\text { o }\end{array}$ & $\begin{array}{l}\text { Name of the } \\
\text { Ligand }\end{array}$ & $\begin{array}{c}\text { Binding } \\
\text { Free } \\
\text { energy } \\
\text { Kcal/ } \\
\text { mol } \\
\end{array}$ & 2D Plot & $\begin{array}{c}\text { Interaction } \\
\text { Surface }\end{array}$ & Docking Pose \\
\hline 1. & Eugenol & -4.08 & w & & \\
\hline 2. & Rutin & -4.55 & \}? & & \\
\hline 3. & Pellitorine & -5.16 & 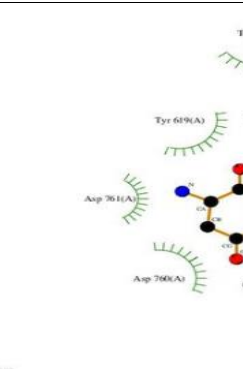 & & \\
\hline 4. & 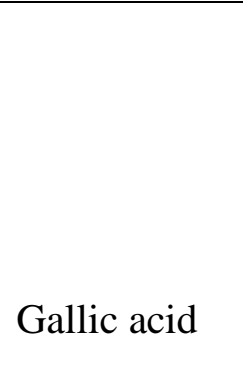 & -4.59 & ${ }^{*}$ & & \\
\hline
\end{tabular}




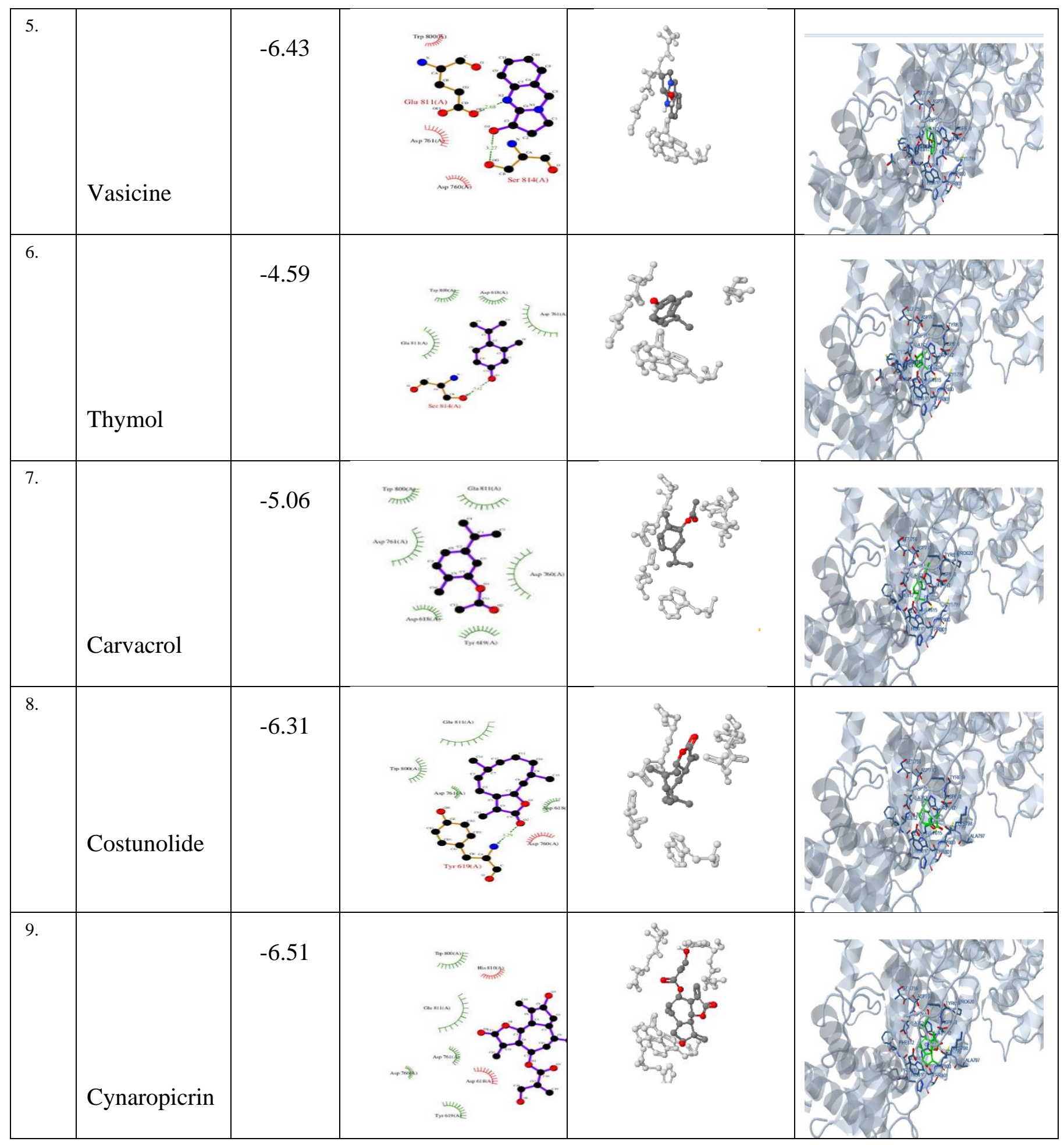




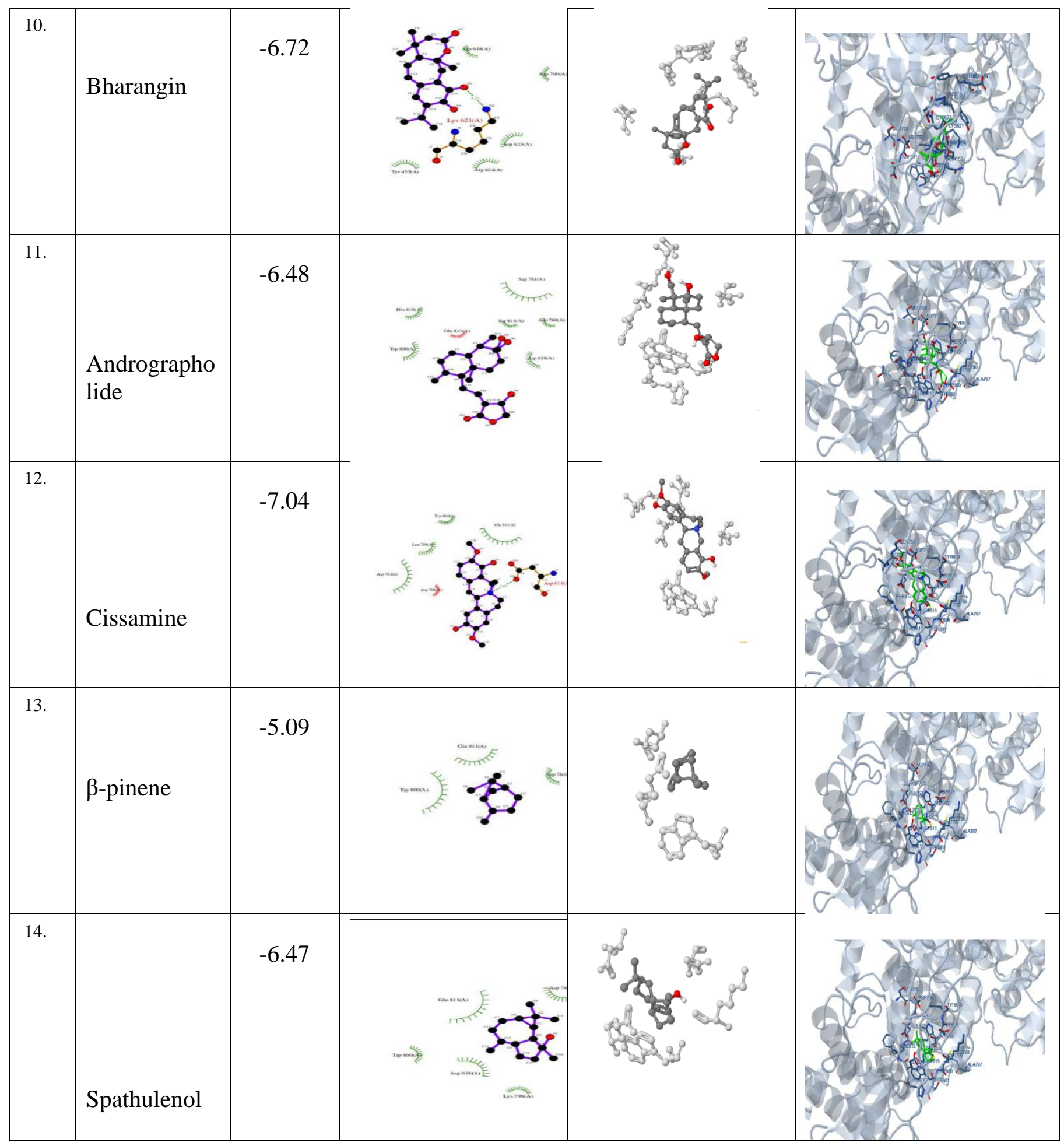




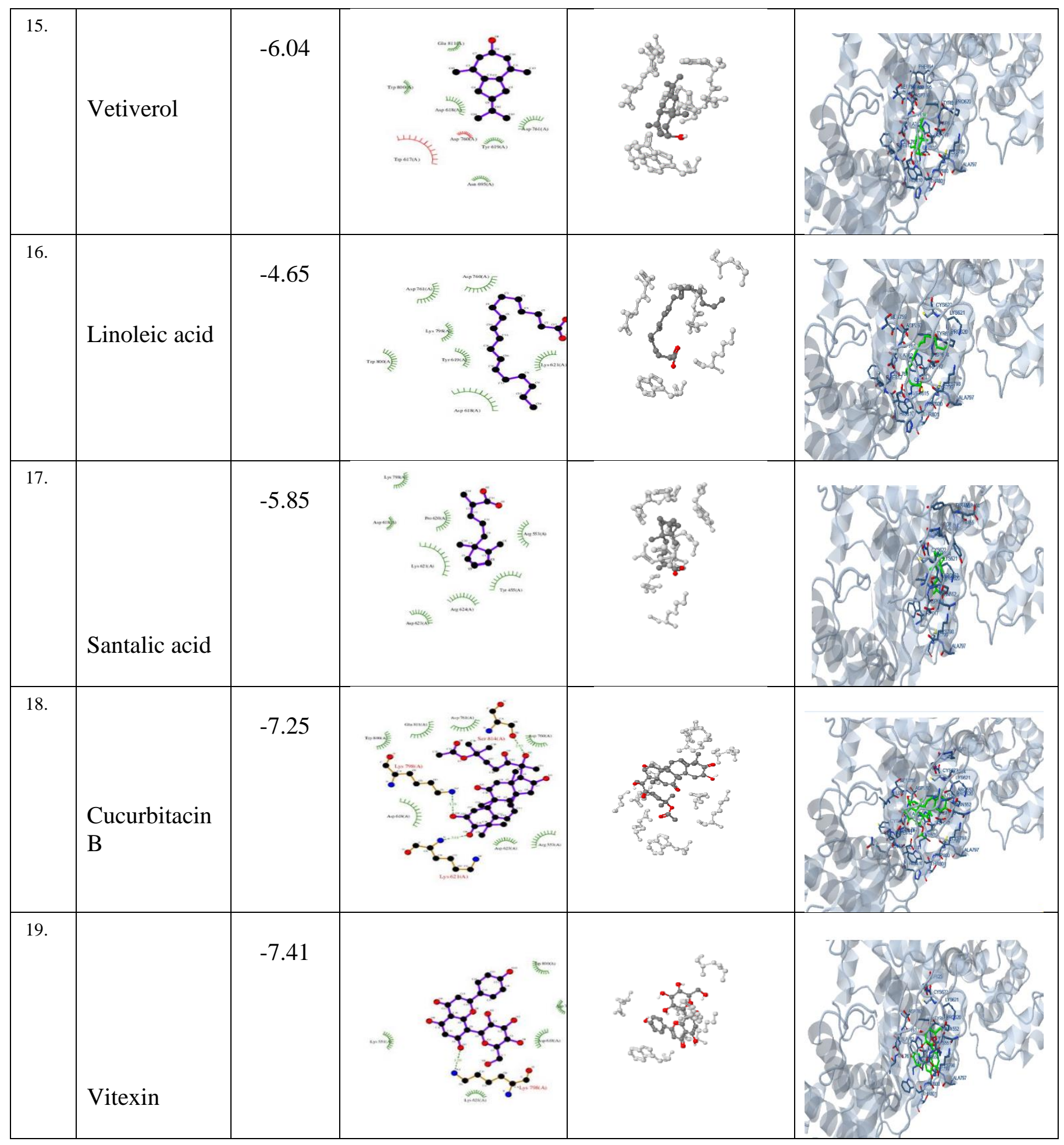




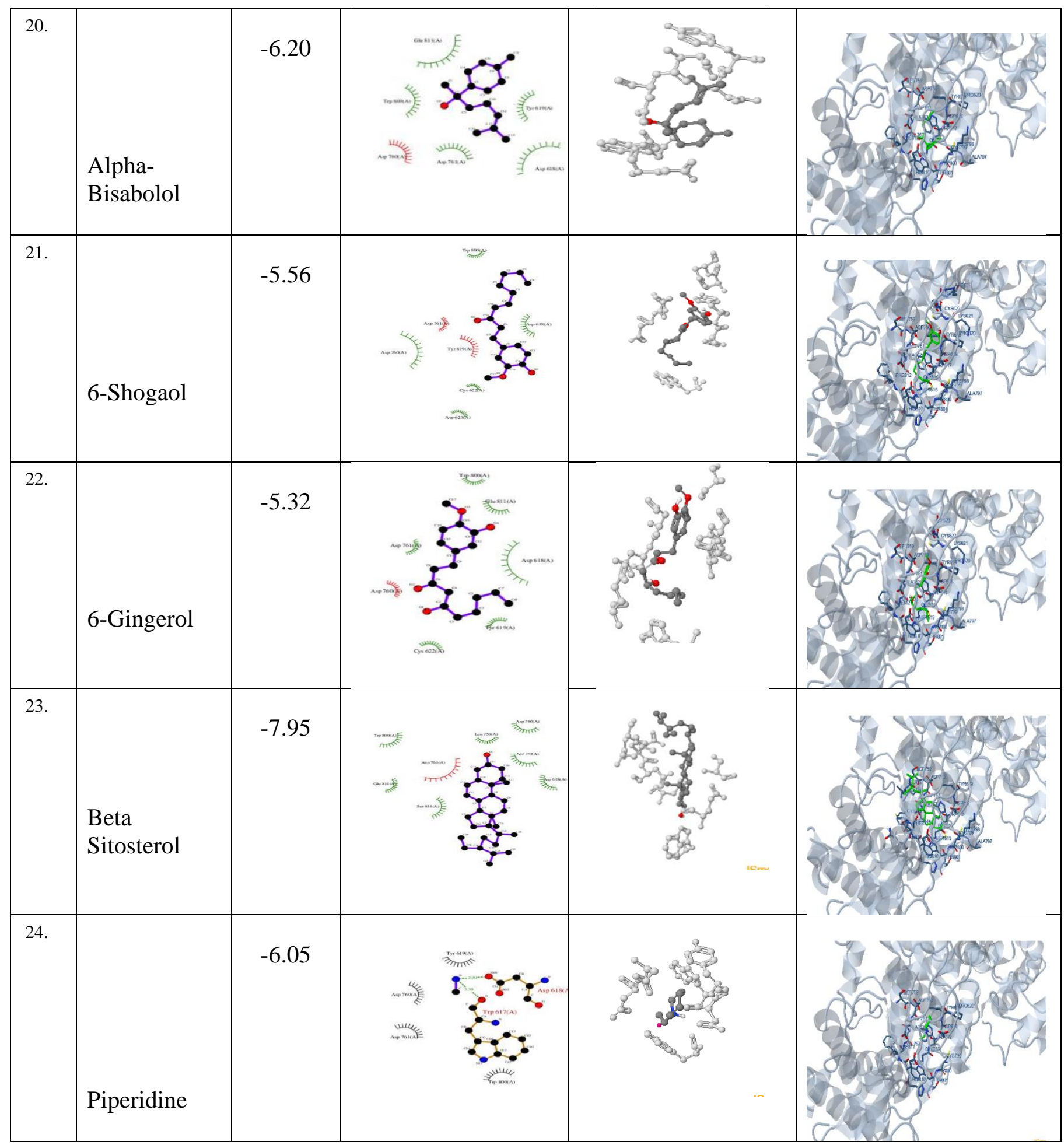




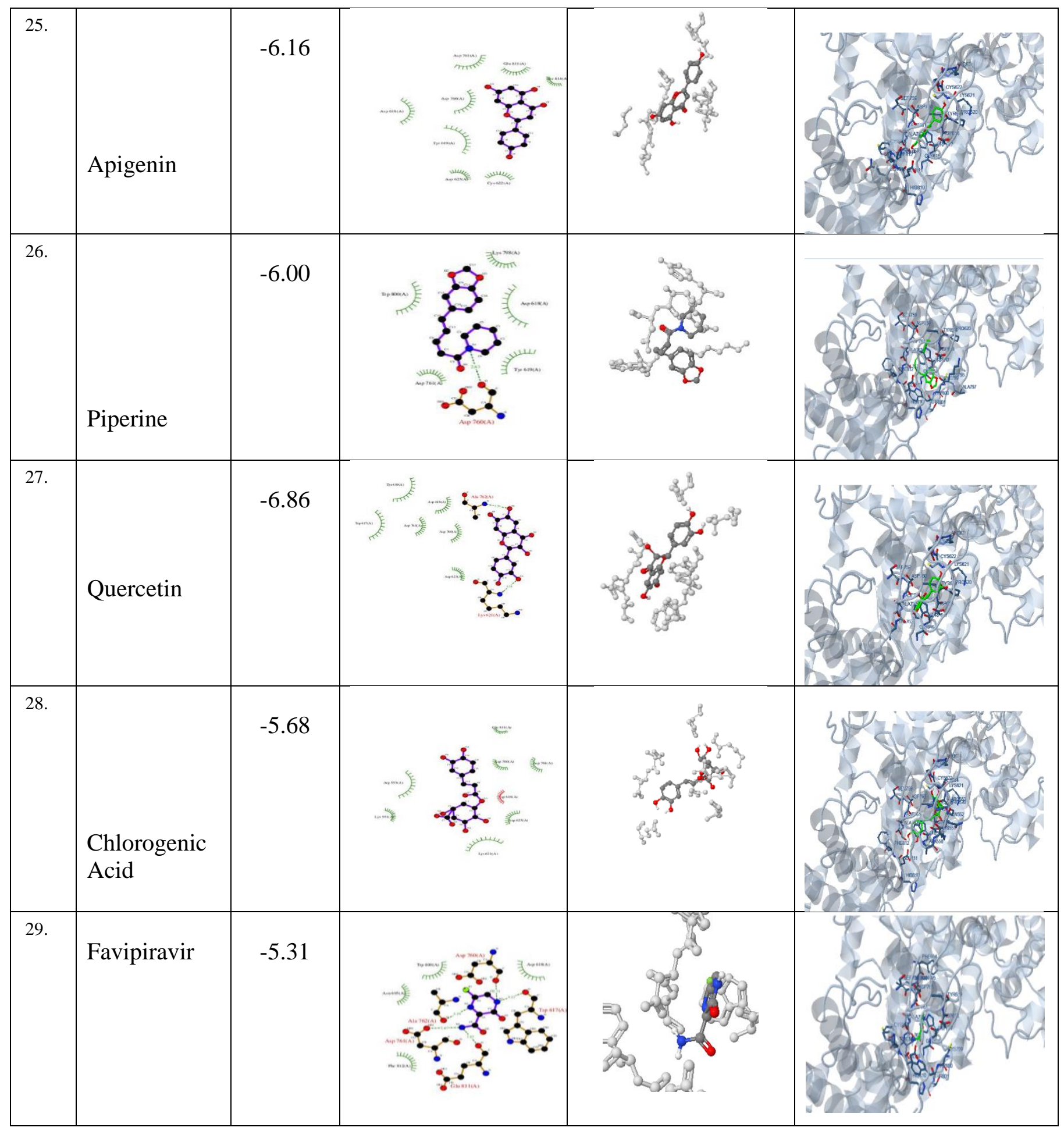


Table 2: Summarizing 2D and 3D structure of Bio-active therapeutic ligand subjected to molecular docking Investigation against SARS-CoV-2 virus spike RNA dependent RNA polymerase (PDB)-6NUR

\begin{tabular}{|c|c|c|c|c|}
\hline S.No & $\begin{array}{l}\text { Name of the } \\
\text { Ligand } \\
\text { Mol. Formula } \\
\text { Mol.Wt }\end{array}$ & 2D structure & 3D Structure & $\begin{array}{c}\text { PubChem } \\
\text { CID } \\
\text { Donor- D } \\
\text { Acceptor- } \\
\text { A } \\
\text { Rotatable- } \\
\text { R }\end{array}$ \\
\hline 1. & $\begin{array}{c}\text { Eugenol } \\
\text { MW: } 164.2 \mathrm{~g} / \mathrm{mol} \\
\text { MF: } \mathrm{C}_{10} \mathrm{H}_{12} \mathrm{O}_{2}\end{array}$ & & & $\begin{array}{l}3314 \\
\mathrm{D}: 1 \\
\mathrm{~A}: 2 \\
\mathrm{R}: 3\end{array}$ \\
\hline 2. & $\begin{array}{c}\text { Rutin } \\
\mathrm{MW}: \\
610.5 \mathrm{~g} / \mathrm{mol} \\
\mathrm{MF}: \mathrm{C}_{27} \mathrm{H}_{30} \mathrm{O}_{16}\end{array}$ & & & $\begin{array}{l}5280805 \\
\text { D:10 } \\
\text { A:16 } \\
\text { R:6 }\end{array}$ \\
\hline 3. & $\begin{array}{c}\text { Pellitorine } \\
\text { MW: } \\
223.35 \mathrm{~g} / \mathrm{mol} \\
\text { MF: } \mathrm{C}_{14} \mathrm{H}_{25} \mathrm{NO}\end{array}$ & & & $\begin{array}{l}5318516 \\
D: 1 \\
A: 1 \\
R: 8\end{array}$ \\
\hline 4. & $\begin{array}{c}\text { Gallic acid } \\
\text { MW: } \\
\text { 170.12g/mol } \\
\text { MF: } \mathrm{C}_{7} \mathrm{H}_{6} \mathrm{O}_{5} \\
\end{array}$ & & & $\begin{array}{l}370 \\
\text { D:4 } \\
\text { A:5 } \\
\text { R:1 }\end{array}$ \\
\hline
\end{tabular}




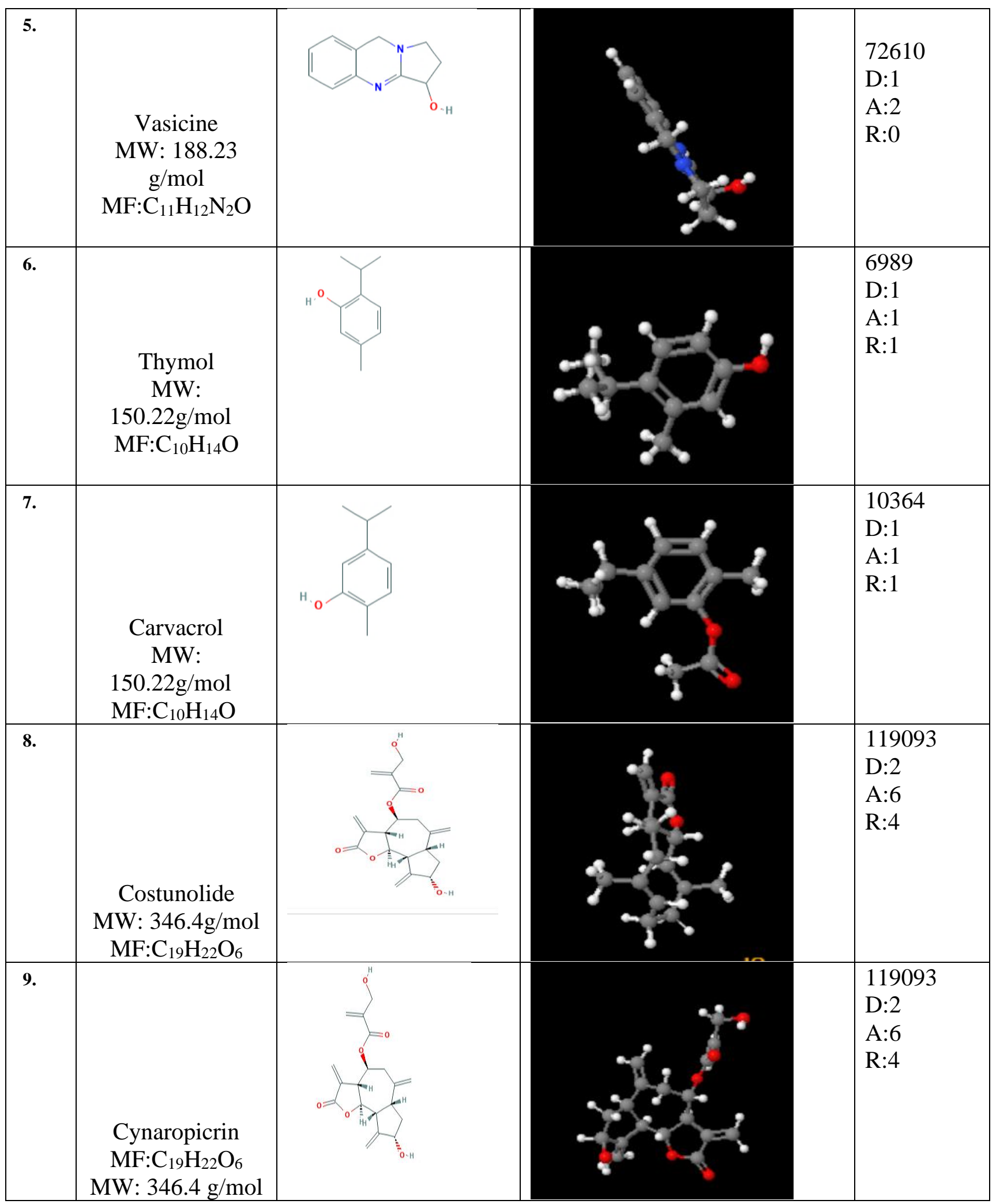




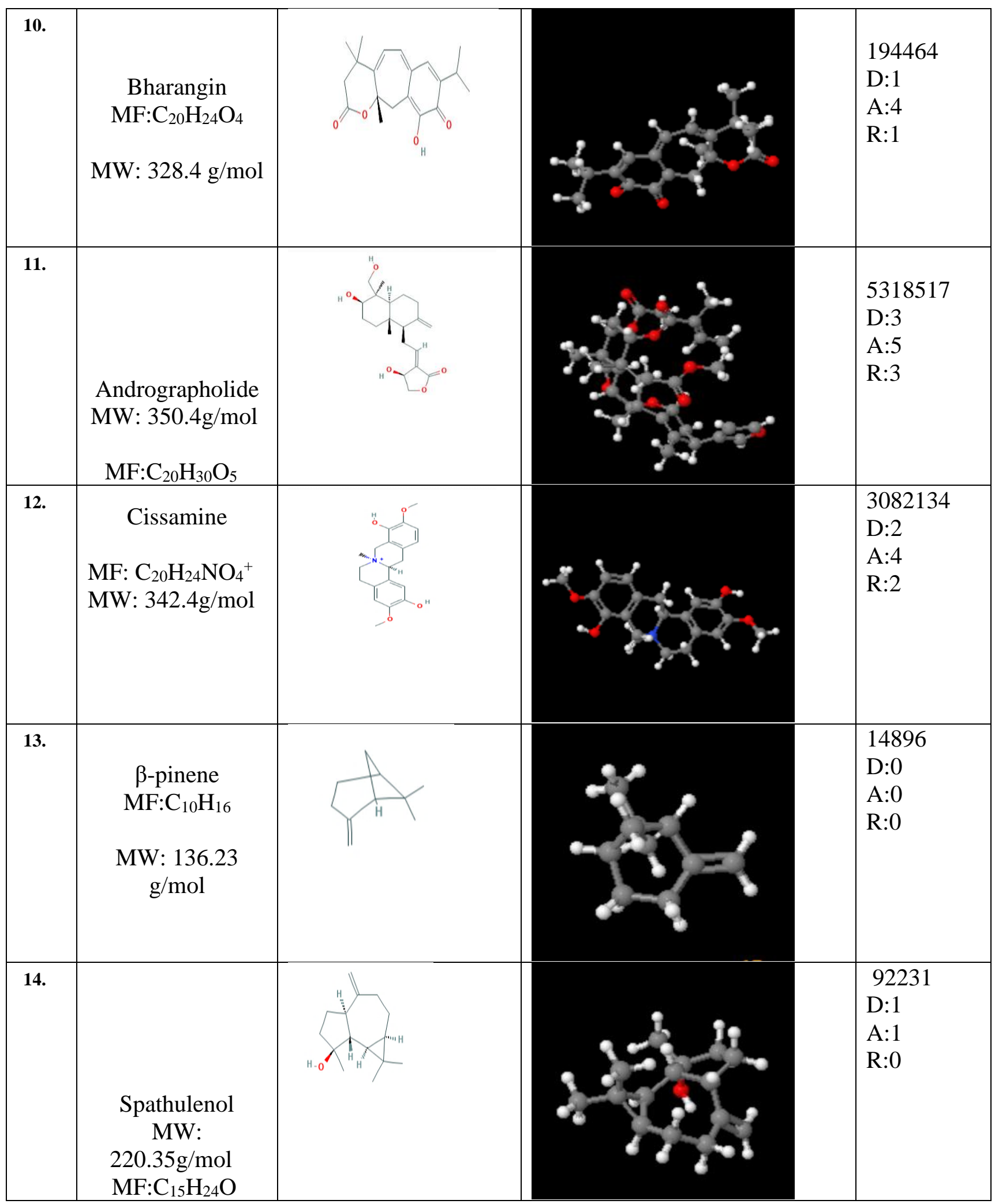




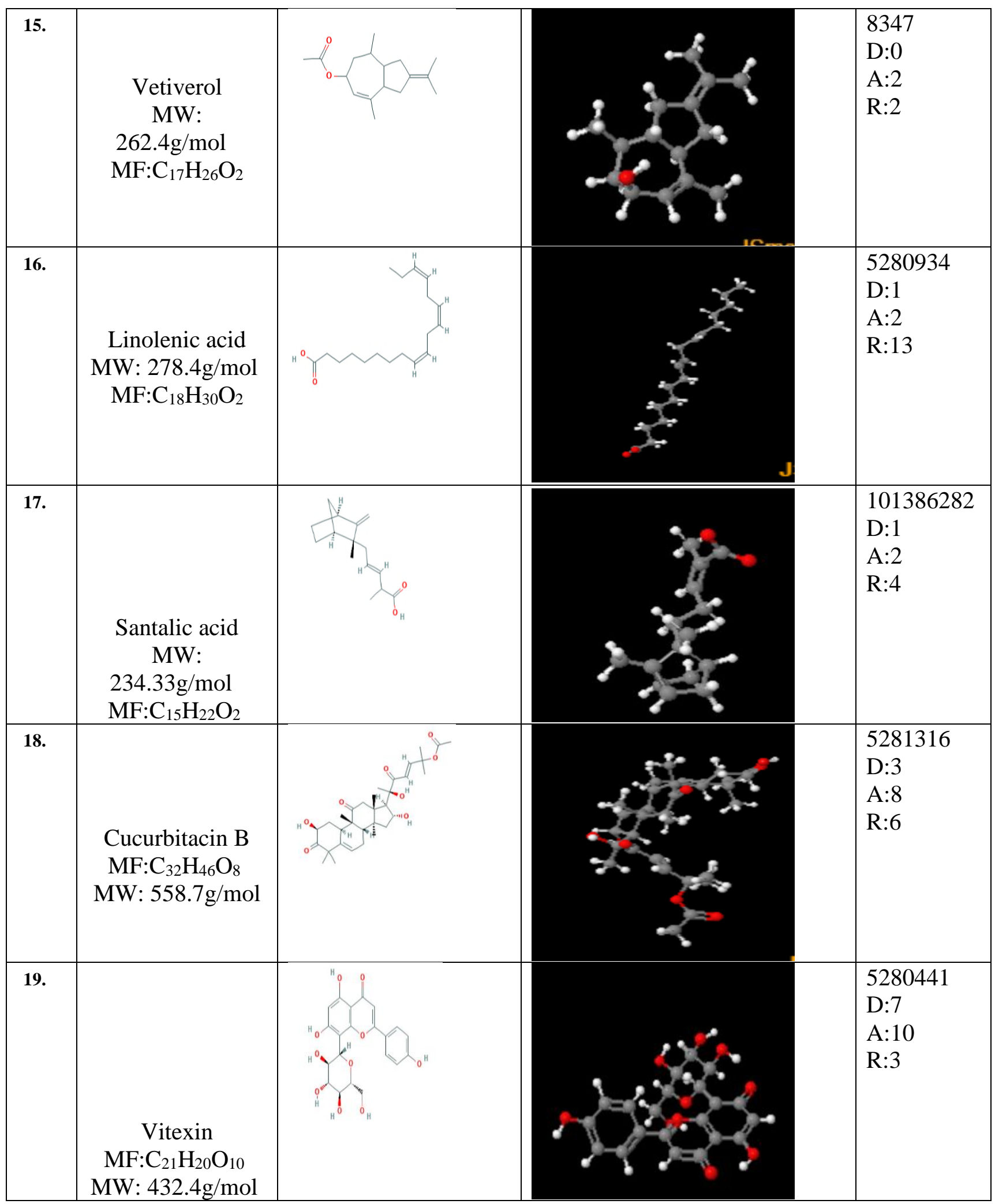




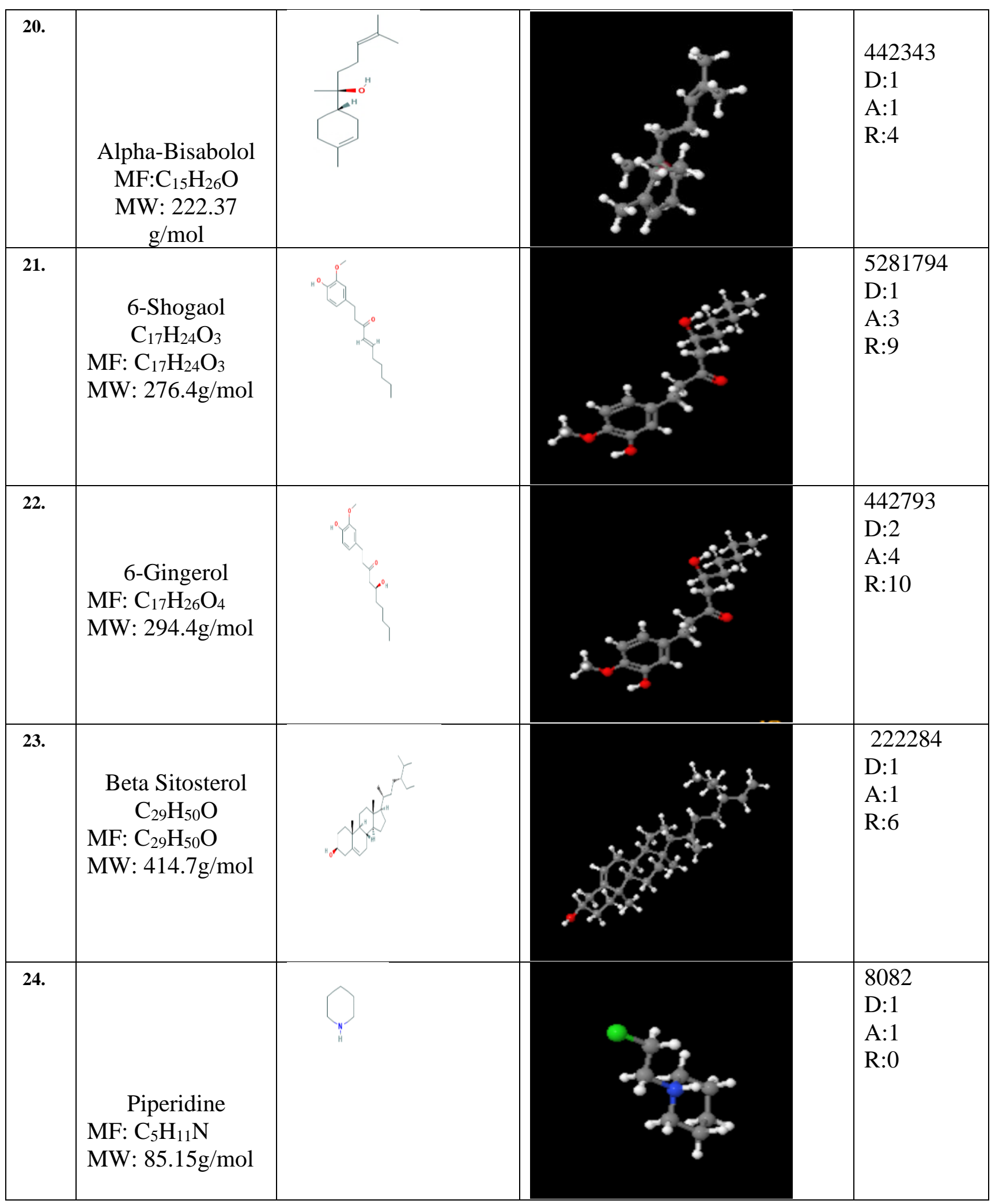




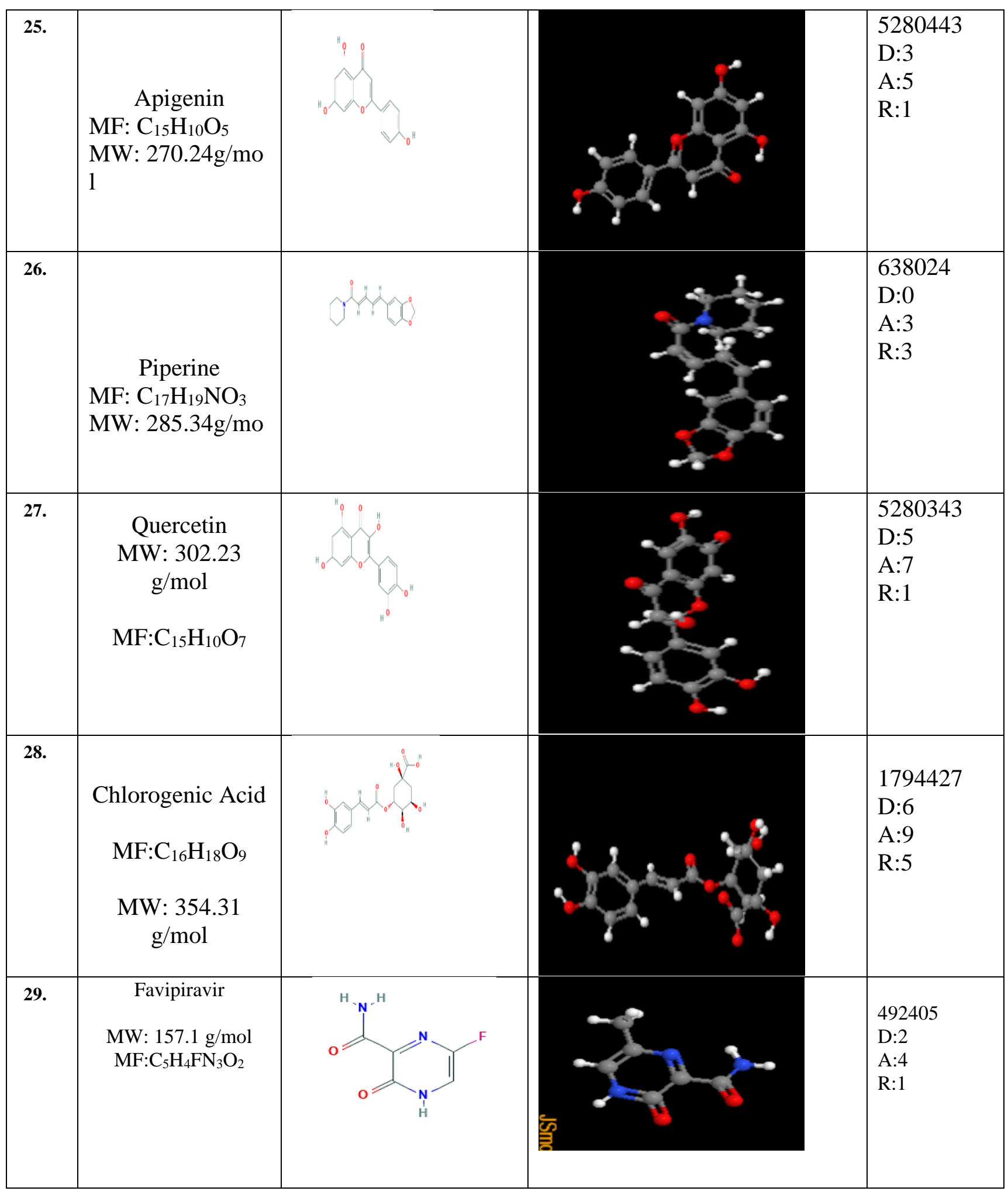


